\title{
Modifications of Cell-wall Polysaccharides during Stipe Elongation in the Basidiomycete Coprinus cinereus
}

\author{
By TAKASHI KAMADA* AND TSUNEO TAKEMARU \\ Department of Biology, Faculty of Science, Okayama University, Okayama 700, Japan
}

(Received 21 May 1982; revised 10 August 1982)

\begin{abstract}
Modifications of cell-wall polysaccharides during stipe elongation in Coprinus cinereus were investigated by gel-filtration and Smith-degradation analyses. During stipe elongation two polysaccharide fractions (I and IVa) decreased in average molecular weight, whereas two other fractions (II and III) increased marginally in molecular weight. The decreases in molecular weight of the former fractions were accompanied by changes in glycosidic linkage composition. Glucans comprised the bulk of all fractions; additionally there was an appreciable contribution from mannose and xylose in fraction II. The results are discussed in relation to the mechanisms of stipe elongation.
\end{abstract}

\section{INTRODUCTION}

Stipe elongation during basidiocarp maturation in Coprinus cinereus is due to the elongation of component cells (Kamada \& Takemaru, 1977a), and thus offers a useful system for clarifying the mechanisms of hyphal cell elongation. In $C$. cinereus the mechanical properties of the stipe cell wall change in parallel with the rate of stipe elongation (Kamada \& Takemaru, 1977a), suggesting that the structure of the stipe cell wall is modified during elongation. Changes in polysaccharide composition have indeed been observed (Kamada \& Takemaru, 1977b), the content of chitin increasing as the stipe elongates (Gooday, 1975).

Recently, wall-bound lytic enzymes have been shown to be involved in the cell-wall metabolism in the $C$. cinereus stipe (Kamada et al., 1980,1982). The lytic enzymes are assumed to modify the component polysaccharides as well as altering the proportional composition of the cell-wall polymers during stipe elongation. Information about the presumed modification of the cell-wall polysaccharides is lacking, although the structures of cell-wall polysaccharides in $C$. cinereus have been investigated (Schaefer, 1977; Bottom \& Siehr, 1979, 1980). The object of the present study was to examine the presumed modification of the cell-wall polysaccharides of the C. cinereus stipe during elongation.

\section{METHODS}

Organism and culture conditions. The wild-type dikaryotic stock $(\# 5026+5132)$ of Coprinus cinereus (Schaeff. ex Fr.) S. F. Gray sensu Konr. (= Coprinus macrorhizus Rea f. microsporus Hongo) was used. For fruiting, an agar block with mycelium $(2 \times 2 \mathrm{~mm})$ was inoculated on the centre of CY-1 medium (containing, per litre, $20 \mathrm{~g}$ glucose, $2 \mathrm{~g}$ peptone, $1 \mathrm{~g}$ yeast extract, $0.46 \mathrm{~g} \mathrm{KH}_{2} \mathrm{PO}_{4}, 1 \mathrm{~g} \mathrm{~K}_{2} \mathrm{HPO}_{4}, 0.5 \mathrm{~g} \mathrm{MgSO}_{4} .7 \mathrm{H}_{2} \mathrm{O}$ and $15 \mathrm{~g}$ agar) in Petri dishes $9 \mathrm{~cm}$ in diameter and incubated at $28^{\circ} \mathrm{C}$ under a regime of $12 \mathrm{~h}$ light/12 h dark (Kamada et al., 1982). Under these conditions, basidiocarp maturation occurred 10 or $11 \mathrm{~d}$ after inoculation.

Cell wall preparation and fractionation. Cell walls were prepared from the middle zone of the stipe, according to a modification of the method of Mahadevan \& Tatum (1965), as described previously (Kamada \& Takemaru, $1977 b$ ).

Cell-wall polysaccharides other than chitin were fractionated as follows. Dilute acid- and alkali-soluble polysaccharides were fractionated according to a minor modification of the method of Wessels (1965): the cell walls $(20-30 \mathrm{mg})$ were extracted with $5 \mathrm{ml} 0.5 \mathrm{M}$-acetic acid at $75^{\circ} \mathrm{C}$ for $30 \mathrm{~min}$. The solubilized material was 
dialysed overnight against distilled water at room temperature and freeze-dried (fraction I), the diffusate being discarded. The residue was washed three times with distilled water and then extracted with $5 \mathrm{ml} 5 \%(\mathrm{w} / \mathrm{v}) \mathrm{KOH}$ at $28{ }^{\circ} \mathrm{C}$ for $18 \mathrm{~h}$. The solubilized material was neutralized with acetic acid and centrifuged at $1500 \mathrm{~g}$ for $10 \mathrm{~min}$. The precipitate was washed three times with distilled water and freeze-dried (fraction II), the supernatant being dialysed and freeze-dried (fraction III). The residue after alkali extraction was further treated with $10 \%$ (w/v) $\mathrm{KOH}$ at $60^{\circ} \mathrm{C}$ for $1 \mathrm{~h}$, washed three times with distilled water, and freeze-dried.

Alkali-insoluble polysaccharides were extracted according to the following procedure: the alkali-insoluble residue $(10 \mathrm{mg})$ was extracted with $95 \%(\mathrm{w} / \mathrm{v})$ dimethyl sulphoxide at room temperature for $16 \mathrm{~h}$ with vigorous shaking (Sietsma \& Wessels, 1981). The solubilized material was dialysed, and the non-diffusible portion retained. The insoluble residue was washed three times with distilled water and the chitin was depolymerized by deacetylation with strong alkali followed by nitrous acid (Sietsma \& Wessels, 1979). The sample, in a screwcapped tube, was treated with $40 \%(\mathrm{w} / \mathrm{v}) \mathrm{NaOH}$ at $100{ }^{\circ} \mathrm{C}$ for $1 \mathrm{~h}$. The solubilized material was dialysed, and retained, the diffusate being discarded. The residue was washed three times with distilled water, and suspended in $1 \mathrm{ml}$ distilled water. Freshly prepared $2 \mathrm{M}-\mathrm{NaNO}_{2}$ solution $(1.5 \mathrm{ml})$ was added to the suspension followed by $0.5 \mathrm{ml}$ $2 \mathrm{M}-\mathrm{HCl}$, and the tube was closed. After incubation at room temperature for $90 \mathrm{~min}$ the tube was opened, and filtered air was bubbled through the suspension for $30 \mathrm{~min}$. The solubilized material was dialysed, and freeze-dried (fraction IVa). The residue was washed three times with distilled water, and then extracted with $2 \mathrm{ml} 5 \%(\mathrm{w} / \mathrm{v}$ ) $\mathrm{KOH}$ at $60{ }^{\circ} \mathrm{C}$ for $20 \mathrm{~min}$. The solubilized material was dialysed, and freeze-dried (fraction IVb).

Gel filtration of the cell-wall polysaccharides. The polysaccharide (approx. $0.5 \mathrm{mg}$ ) was dissolved in $0.3 \mathrm{ml} 1 \mathrm{M}$ $\mathrm{NaOH}$ and adjusted to $\mathrm{pH} 9.5$ with $2 \%(\mathrm{w} / \mathrm{v})$ boric acid. The solution was applied to a Sepharose CL-2B or a Sepharose CL-6B column $(1.1 \times 80 \mathrm{~cm})$ previously equilibrated with sodium borate $/ \mathrm{NaOH}$ buffer $(0.05 \mathrm{M}$ with respect to borate; $\mathrm{pH} 9 \cdot 5$ ). The columns were calibrated with dextran standards (Pharmacia) with average molecular weights of $2 \times 10^{6}, 5.1 \times 10^{5}, 6.56 \times 10^{4}$ and $1.05 \times 10^{4}$. The elution rate was $4-5 \mathrm{ml} \mathrm{h}^{-1}$. Fractions of $2 \mathrm{ml}$ were collected and analysed for carbohydrate content or sugar composition.

Analysis of sugar composition of the cell-wall polysaccharides. Polysaccharide was hydrolysed with $3 \mathrm{M}-\mathrm{HCl}$ at $100^{\circ} \mathrm{C}$ for $3 \mathrm{~h}$ and neutralized with $\mathrm{NaOH}$ according to Griggs et al. (1971). The resulting monosaccharides were converted to their corresponding alditol acetate derivatives according to the procedure of Griggs et al. (1971) and analysed by gas chromatography.

Smith degradation. The polysaccharide $(1 \mathrm{mg}$ ) was oxidized with $1 \mathrm{ml} 0.025 \mathrm{M}$-sodium metaperiodate in the dark at $4{ }^{\circ} \mathrm{C}$ for $5 \mathrm{~d}$. Bottom \& Siehr (1979) have shown that the oxidation of the cell-wall polysaccharides of $C$. cinereus is completed under these conditions. The oxidized polysaccharide was reduced with $\mathrm{NaBH}_{4}$ and hydrolysed with $0.25 \mathrm{M}-\mathrm{H}_{2} \mathrm{SO}_{4}$ at $100^{\circ} \mathrm{C}$ for $8 \mathrm{~h}$ according to Misaki et al. (1974). The hydrolysate was neutralized with $\mathrm{BaCO}_{3}$, and after the removal of $\mathrm{BaSO}_{4}$ the sugars in the hydrolysate were reduced to their corresponding alditols with $\mathrm{NaBH}_{4}$. The mixture of polyalcohols was acetylated according to the method of Misaki et al. (1974) and analysed by gas chromatography.

Gas chromatography. Gas chromatography was carried out with a Hitachi 163 gas chromatograph, using a glass column $(3 \mathrm{~mm} \times 2 \mathrm{~m}$ ) packed with a mixture of $0.2 \%$ ethylene glycol succinate, $0.2 \%$ ethylene glycol adipate and $1.4 \%$ silicone XE-60 (Griggs et al., 1971) on Chromosorb W Aw DMCS. Alditol acetate derivatives of the sugars obtained by the $\mathrm{HCl}$ hydrolysis were separated on a temperature gradient of $150-205^{\circ} \mathrm{C}$, programmed to rise at a rate of $1{ }^{\circ} \mathrm{C} \mathrm{min}^{-1}$. Acetylated Smith degradation products were separated on a temperature gradient of $85-$ $205^{\circ} \mathrm{C}$, programmed to rise at a rate of $5^{\circ} \mathrm{C} \mathrm{min}^{-1}$.

Chemical assay. Total carbohydrate content was determined with the anthrone reagent (Fairbairn, 1953), using glucose as standard.

\section{RESULTS}

\section{Stipe elongation}

Under the culture conditions described in Methods, stipe elongation during basidiocarp maturation proceeds in a synchronous manner (Kamada \& Takemaru, 1977a). The elongation rate of the middle zone of the stipe increased up to $15 \mathrm{~h}$ after the start of illumination on the day of maturation and then decreased rapidly. Elongation ceased by $21 \mathrm{~h}$ after the start of illumination.

\section{Polysaccharide composition of the stipe cell wall}

The cell-wall polysaccharides other than chitin were fractionated as described in Methods, and the polysaccharide contents of the respective fractions were followed during stipe elongation (Fig. 1). The contents in fractions I, II and III during elongation were consistent with previous results (Kamada \& Takemaru, 1977b). Dimethyl sulphoxide extracted very little 


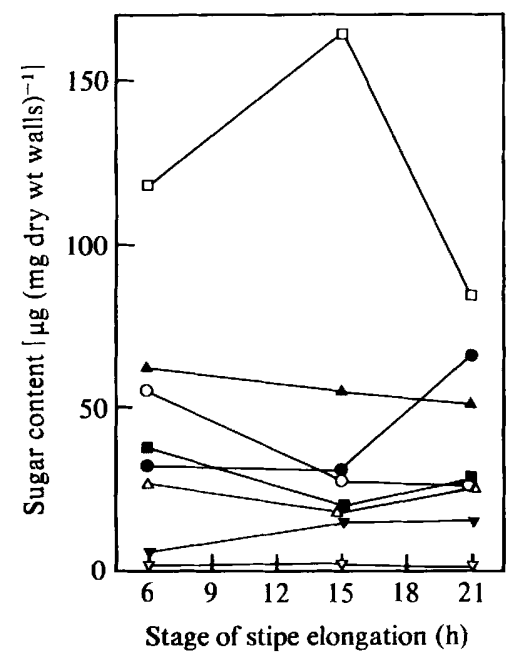

Fig. 1. Amounts of polysaccharide in fractions from the Coprinus cinereus stipe. The stipe cell walls were fractionated as described in Methods, and the polysaccharide contents in fractions I (O), II (O),

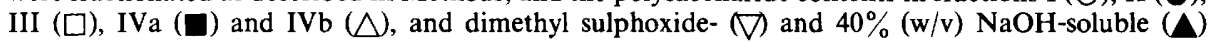
portions, as well as the insoluble residue after the fractionation $(\nabla)$, were followed during stipe elongation. The content is expressed as $\mu \mathrm{g}$ anthrone-positive materials per $\mathrm{mg}$ dry weight of cell walls. The average of at least four measurements is given for each plot. The abscissa shows hours after the start of illumination on the day of basidiocarp maturation.

polysaccharide from the alkali-insoluble residue of the cell wall, and the subsequent treatment with $40 \%$ (w/v) NaOH at $100{ }^{\circ} \mathrm{C}$ extracted the majority of the polysaccharide from the residue. Both the contents in fractions IVa and IVb were approximately half of the content of $40 \%$ $\mathrm{NaOH}$-soluble polysaccharide.

\section{Molecular weight distribution of the cell-wall polysaccharides}

The molecular weight distributions of the polysaccharides in the five fractions were examined by gel filtration. Fractions I and IVa, with relatively smaller molecular weights, and fractions II, III and IVb, with larger molecular weights, were chromatographed on Sepharose CL-6B and Sepharose CL-2B, respectively (Fig. 2). All the fractions except fraction I had a single major peak. There appeared to be at least two peaks for fraction I. As the stipe elongated, the average molecular weights of fractions I and IVa clearly decreased, whereas those of fractions II and III appeared to increase slightly. The molecular weight distribution of fraction IVb did not change.

\section{Sugar composition of the cell-wall polysaccharides}

Gas chromatography of the hydrolysates of the polysaccharides revealed that the major component of fractions I, III, IVa and IVb was glucose, with trace $(<1 \%)$ amounts of rhamnose, arabinose, xylose, mannose and galactose. Fraction II contained, in addition to glucose, substantial amounts of mannose and xylose, both of which decreased in quantity as the stipe elongated (Fig. 3). The molar ratio of mannose to xylose (approx. $6: 1$ ) was constant during elongation. The polysaccharide in fraction II was fractionated on a Sepharose CL-2B column, and the sugar composition of each fraction was determined. Xylose and mannose were eluted in the same position, but glucose was eluted earlier (Fig. 4). These results suggest that fraction II consists of glucan and xylomannan. Xylomannan has been suggested as a component of the alkali-soluble cell-wall fraction of $C$. cinereus (Bottom \& Siehr, 1979), and demonstrated in the cell walls of two other basidiomycetes, Polyporus tumulosus (Ralph \& Bender, 1965; Angyal et al., 1974) and Armillaria mellea (Bouveng et al., 1967). 


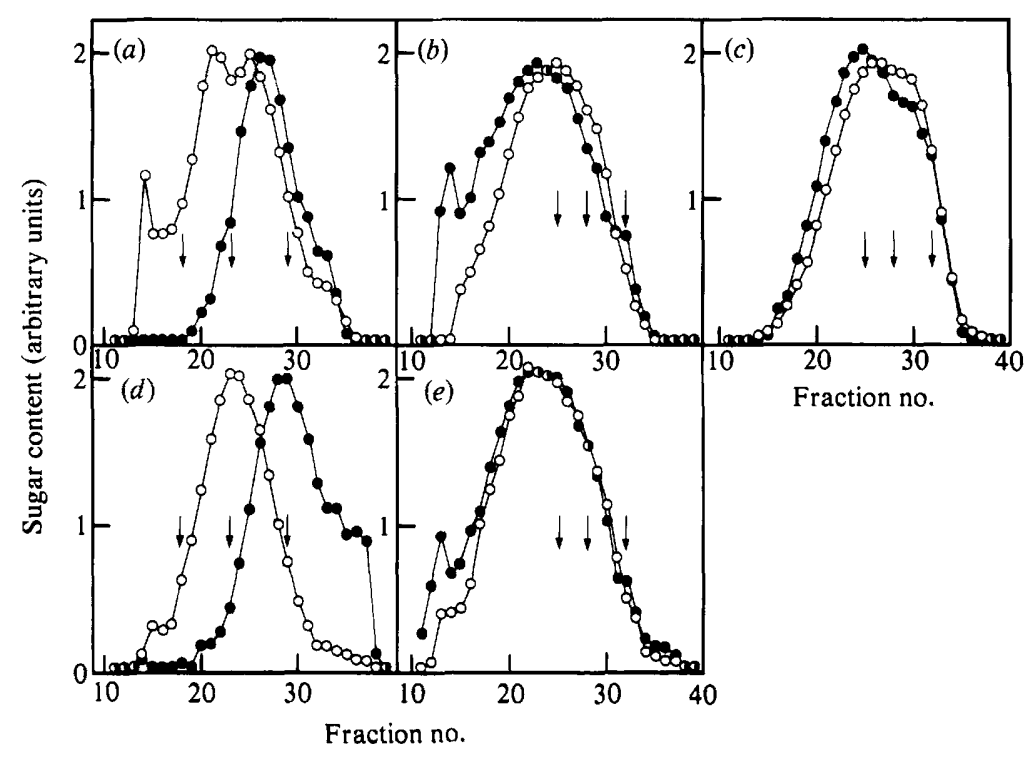

Fig. 2. Molecular weight distributions of the cell-wall polysaccharides of the $C$. cinereus stipes at the $6 \mathrm{~h}$ $(O)$ and $21 \mathrm{~h}(O)$ stages. Fractions I $(a)$ and IVa $(d)$, and fractions II $(b)$, III $(c)$ and IVb $(e)$ were chromatographed on Sepharose CL-6B and Sepharose CL-2B, respectively, as described in Methods. Fractions of $2 \mathrm{ml}$ were collected and analysed with the anthrone reagent. The arrows in $(a)$ and $(d)$ indicate the elution positions of (left to right) dextrans with molecular weights of $5 \cdot 1 \times 10^{5}, 6.56 \times 10^{4}$ and $1.05 \times 10^{4}$; the arrows in $(b),(c)$ and $(e)$ indicate those of (left to right) dextrans of molecular weight $2 \times 10^{6}, 5 \cdot 1 \times 10^{5}$ and $6.56 \times 10^{4}$.

\section{Glycosidic linkage composition of the cell-wall polysaccharides}

Cell-wall polysaccharides other than chitin in $C$. cinereus have been shown to contain $\beta-(1 \rightarrow 3)$, $\beta-(1 \rightarrow 6)$ and $\alpha-(1 \rightarrow 4)$ linkages (Bottom \& Siehr, 1979, 1980). To study the glycosidic linkage compositions of the five polysaccharide fractions and their changes during stipe elongation, the polysaccharides from stipes at various stages of elongation were subjected to Smith degradation, and the products were analysed (Fig. 5). The degradation of $(1 \rightarrow 3)-,(1 \rightarrow 4)$ - and $(1 \rightarrow 6)$-linked glucose residues within a polysaccharide liberates glucose, erythritol and glycerol, respectively; the non-reducing end of the polymer also liberates glycerol. Smith degradation of fraction I, which is primarily glucan, yielded glucose, erythritol and glycerol. As the stipe elongated, the proportion of erythritol greatly decreased, whereas those of glucose and glycerol increased. This suggests that the polysaccharide contains $(1 \rightarrow 3),(1 \rightarrow 4)$ and $(1 \rightarrow 6)$ linkages, and that the proportion of $(1 \rightarrow 4)$ linkages decreases as stipe elongation proceeds. In the degradation products of fraction II, glucose and mannose were recovered in substantially the same proportion as in the hydrolysate of the polysaccharide without periodate treatment (also see Fig. 3), and only a small amount of glycerol and a trace of erythritol were detected. This suggests that both glucose and mannose are mainly $(1 \rightarrow 3)$ linked. The glycosidic linkage of xylose could not be determined, because the xylose content of the fraction was too small. Fraction III and fraction IVb polysaccharides, both of which are glucans, appeared to contain large proportions of $(1 \rightarrow 3)$ and $(1 \rightarrow 6)$ linkages and a trace of $(1 \rightarrow 4)$ linkage. The ratios of $(1 \rightarrow 3)$ to $(1 \rightarrow 6)$ linkages in the polysaccharides were substantially constant during stipe elongation. Fraction IVa polysaccharide appeared to contain $(1 \rightarrow 3)$ and $(1 \rightarrow 6)$ linkages, and the ratio of $(1 \rightarrow 3)$ to $(1 \rightarrow 6)$ linkages gradually increased during stipe elongation. 


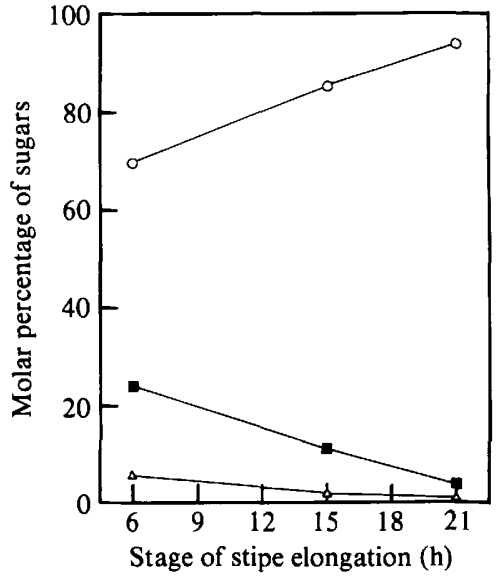

Fig. 3

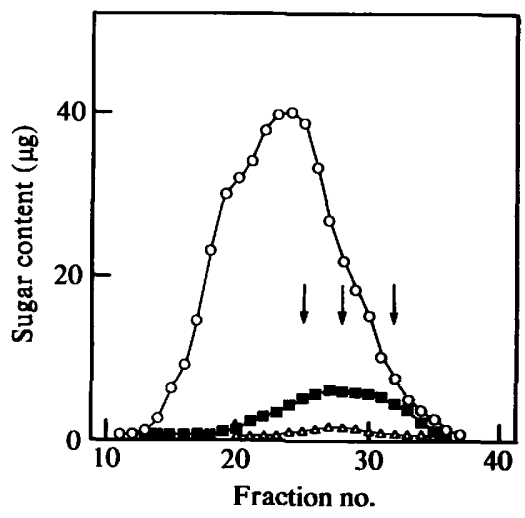

Fig. 4

Fig. 3. Change in sugar composition of fraction II polysaccharide during stipe elongation in C. cinereus. The polysaccharide was hydrolysed and analysed for sugar composition by gas chromatography, as described in Methods. $O$, Glucose; $\square$, mannose; $\triangle$, xylose. The abscissa shows hours after the start of illumination on the day of basidiocarp maturation.

Fig. 4. Elution pattern of fraction II polysaccharides of the $C$. cinereus stipe at the $15 \mathrm{~h}$ stage. Fraction II was chromatographed on a Sepharose CL-2B column and fractions of $2 \mathrm{ml}$ were collected, as described in Methods. The polysaccharide in each fraction was hydrolysed and then analysed for sugar composition by gas chromatography, as described in Methods. $O$, Glucose; $\square$, mannose; $\triangle$, xylose. The arrows indicate the elution positions of (left to right) dextrans of molecular weight $2 \times 10^{6}, 5 \cdot 1 \times$ $10^{5}$ and $6.56 \times 10^{4}$.

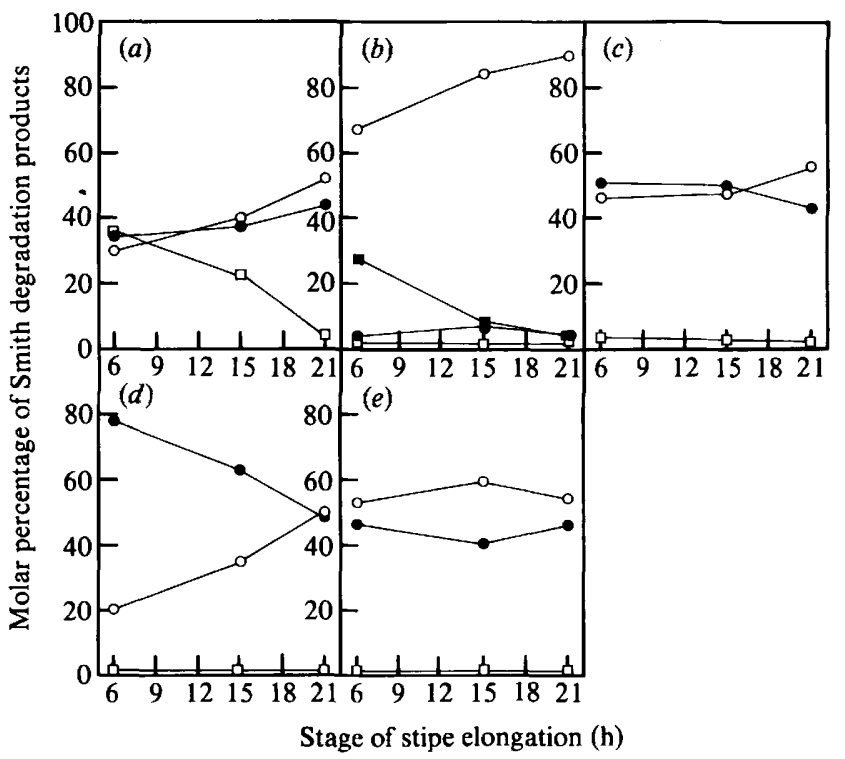

Fig. 5. Changes in molar ratio of the Smith degradation products of the cell-wall polysaccharides during stipe elongation in C. cinereus. The polysaccharides in fractions I (a), II (b), III $(c)$, IVa $(d)$ and IVb $(e)$ were subjected to Smith degradation, and the respective products were analysed by gas chromatography, as described in Methods. $\bigcirc$, glucose; $\odot$, glycerol; $\square$, erythritol; $\square$, mannose. The abscissas show hours after the start of illumination on the day of basidiocarp maturation. 


\section{DISCUSSION}

The stipe cell wall in $C$. cinereus seems different in glycosidic linkage composition from the cell wall of vegetative mycelium. One of the two alkali-soluble fractions from the stipe cell wall (fraction II) contained a mainly ( $1 \rightarrow 3$ )-linked glucan and another (fraction III) was primarily a glucan mainly containing $(1 \rightarrow 3)$ and $(1 \rightarrow 6)$ linkages (Fig. 5). In contrast, an alkali-soluble polysaccharide from the cell walls of dikaryotic mycelium has been reported to contain $\beta-(1 \rightarrow 3)$ linked glucose units with $14 \%$ of the sugars having $\beta-(1 \rightarrow 6)$-linked branch points (Schaefer, 1977 ), and the polysaccharide from monokaryotic mycelium contains a large proportion of $\alpha$ $(1 \rightarrow 4)$-linked glucose residues (Bottom \& Siehr, 1979). The glucan from the alkali-insoluble residue of the stipe cell walls also differs in structure from that of monokaryotic mycelium in that the latter contains a large proportion of $\alpha-(1 \rightarrow 4)$ linkages (Bottom \& Siehr, 1980). These differences are probably a reflection of the cell-wall differentiation associated with developmental phases, as pointed out by Marchant (1978), though differences in strains used and/or the procedure adopted for polysaccharide preparation may also have been responsible.

The present study shows that in fractions I and IVa the proportions of $(1 \rightarrow 4)$ and $(1 \rightarrow 6)$ linkages, respectively, decrease during stipe elongation (Fig. 5). Wall-lytic enzymes could be involved in the changes in glycosidic linkage composition, because both polysaccharides decrease in molecular weight during stipe elongation (Fig. 2). Since fraction I is heterogeneous (Fig. 2), it is not known whether the modification of fraction I polysaccharide is due to the preferential cleavage of $(1 \rightarrow 4)$ linkages within a glucan or to the preferential degradation of some component polysaccharide which contains a high proportion of $(1 \rightarrow 4)$ linkages. On the other hand, fraction IVa polysaccharide appears to be relatively homogeneous (Fig. 2), and thus its modification may be due to the preferential cleavage of $(1 \rightarrow 6)$ linkages within the glucan. Further analyses are required to understand the precise mode of the polysaccharide modification.

The mechanical properties of the stipe cell wall in $C$. cinereus change in parallel with the rate of stipe elongation (Kamada \& Takemaru, 1977a). The cleavage of $(1 \rightarrow 6)$ linkages in fraction IVa polysaccharide may be related to these changes, since fraction IVa polysaccharide is assumed to be chemically linked to chitin filaments (Sietsma \& Wessels, 1979), which are a skeletal component and lie predominantly transversely in the stipe cell wall (Gooday, 1975).

Bartnicki-Garcia (1973) proposed a model in which cell-wall lytic enzymes are suggested to attack a skeletal component by splitting either inter- or intramolecular bonds during cell-wall growth. Wessels (1969) previously suggested that R-glucanase in the basidiomycete Schizophyllum commune, which is classified as a $\beta-(1 \rightarrow 6)$ glucanase, plays an important role as an initiator of wall softening by the lysis of alkali-resistant cell-wall $\beta$-glucans. Analyses in progress on mutants of $C$. cinereus with defective stipe elongation may further our understanding of the role of polysaccharide modifications in the mechanism of stipe elongation.

We wish to thank Dr G. W. Gooday of the University of Aberdeen for his critical reading of the manuscript. This work was supported in part by a Grant-in-Aid for Scientific Research to T.T. (no. 56480011) from the Ministry of Education, Science and Culture, Japan.

\section{REFERENCES}

Angyal, S. J., Bender, V. J. \& RalPh, B. J. (1974). Structure of polysaccharides from the Polyporus tumulosus cell wall. Biochimica et biophysica acta $\mathbf{3 6 2}$, 175-187.

BARTNICKI-GARCIA, S. (1973). Fundamental aspects of hyphal morphogenesis. Symposia of the Society for General Microbiology 23, 245-267.

BotTom, C. B. \& SIEHR, D. J. (1979). Structure of an alkali-soluble polysaccharide from the hyphal wall of the basidiomycete Coprinus macrorhizus var. microsporus. Carbohydrate Research 77, 169-181.
BoTtOM, C. B. \& SiEHR, D. J. (1980). Structure and composition of the alkali-insoluble cell wall fraction of Coprinus macrorhizus var. microsporus. Canadian Journal of Biochemistry 58, 147-153.

Bouveng, H. O., Fraser, R. N. \& Lindberg, B. (1967). Polysaccharides elaborated by Armillaria mellea (Tricholomataceae). Part II. Water-soluble mycelium polysaccharides. Carbohydrate Research 4, 20-31.

FAIRBAIRN, N. (1953). A modified anthrone reagent. Chemistry and Industry 72, 86. 
Gooday, G. W. (1975). The control of differentiation in fruit bodies of Coprinus cinereus. Reports of the Tottori Mycological Institute (Japan) 12, 151-160.

Griggs, L. J., Post, A., White, E. R., Finkelstein, J. A., Moeckel, W. E., Holden, K. G., Zarembo, J. E. \& WeISBACH, J. A. (1971). Identification and quantitation of alditol acetates of neutral and amino sugars from mucins by automated gas-liquid chromatography. Analytical Biochemistry 43, 369 381 .

Kamada, T. \& TAKemaru, T. (1977a). Stipe elongation during basidiocarp maturation in Coprinus macrorhizus: mechanical properties of stipe cell wall. Plant and Cell Physiology 18, 831-840.

Kamada, T. \& Takemaru, T. (1977b). Stipe elongation during basidiocarp maturation in Coprinus macrorhizus: changes in polysaccharide composition of stipe cell wall during elongation. Plant and Cell Physiology 18, 1291-1300.

Kamada, T., Fuji, T. \& Takemaru, T. (1980). Stipe elongation during basidiocarp maturation in $\mathrm{Co}$ prinus macrorhizus: changes in activity of cell wall lytic enzymes. Transactions of the Mycological Society of Japan 21, 359-367.

Kamada, T., Hamada, Y. \& Takemaru, T. (1982). Autolysis in vitro of the stipe cell wall in Coprinus macrorhizus. Journal of General Microbiology 128 , 1041-1046.

Mahadevan, P. R. \& Tatum, E. L. (1965). Relationship of the major constituents of the Neurospora crassa cell wall to wild-type and colonial morphology. Journal of Bacteriology 90, 1073-1081.

MARCHANT, R. (1978). Wall composition of monokaryons and dikaryons of Coprinus cinereus. Journal of General Microbiology 106, 195-199.

Misaki, A., Seto, N. \& Azuma, I. (1974). Structure and immunological properties of D-arabino-D-galactans isolated from cell walls of Mycobacterium species. Journal of Biochemistry 76, 15-27.

RALPH, B. J. \& BENDER, V. J. (1965). Isolation of two new polysaccharides from the cell wall of Polyporus tumulosus. Chemistry and Industry, 1181.

SCHAEFER, H. P. (1977). An alkali-soluble polysaccharide from the cell walls of Coprinus lagopus. Archives of Microbiology 113, 79-82.

Sietsma, J. H. \& Wessels, J. G. H. (1979). Evidence for covalent linkages between chitin and $\beta$-glucan in a fungal wall. Journal of General Microbiology 114, 99108.

Sietsma, J. H. \& Wessels, J. G. H. (1981). Solubility of $(1 \rightarrow 3)-\beta$-D $/(1 \rightarrow 6)-\beta$-D-glucan in fungal walls: importance of presumed linkage between glucan and chitin. Journal of General Microbiology 125, 209-212.

Wessels, J. G. H. (1965). Morphogenesis and biochemical processes in Schizophyllum commune Fr. Wentia 13, 1-113.

Wessels, J. G. H. (1969). A $\beta$-1,6-glucan glucanohydrolase involved in hydrolysis of cell-wall glucan in Schizophyllum commune. Biochimica et biophysica acta 178, 191-193. 